\title{
LEIOMIOMA PERFURADO DO INTESTINO DELGADO
}

\author{
PERFORATED SMALL INTESTINE LEIOMYOMA
}

\author{
Antonio Cavalcanti de Albuquerque Martins, TCBC-PE ${ }^{1}$ \\ Carolina Martins ${ }^{2}$ \\ Helio Flavio Faustino Santos ${ }^{3}$
}

\section{INTRODUÇÃO}

Apesar do intestino delgado contribuir com $80 \%$ do comprimento e $90 \%$ da superfície mucosa intestinal, as neoplasias desse segmento são raras. No intestino delgado originam-se 3-6\% dos tumores e 1\% das neoplasias malignas gastrointestinais. A maioria dos casos é de achado operatório ou de autópsia ${ }^{1,2}$.

$\mathrm{O}$ leiomioma e o mais comum dos tumores benignos (35\%), sendo usualmente encontrado no segmento jejuno-ileal. Os sintomas mais prevalentes das neoplasias intestinais são a dor abdominal, causada por obstrução parcial ou intussepção, e a hemorragia digestiva ${ }^{1}$. Essa ultima pode ser insidiosa ou causar choque hemorrágico em poucas horas. A perfuração é muito rara, visto que apenas sete casos foram relatados. Todos tumores benignos perfurados relatados na literatura eram leiomiomas (exceto um neurofibroma) ${ }^{2,3}$.

\section{RELATO DO CASO}

Paciente masculino, branco, 45 anos, natural e procedente do Recife. Admitido com queixa de dor abdominal súbita e febre há 20 horas. Ao exame físico, o paciente mostrava-se com fácies de dor, desidratado, taquipnêico e taquicárdico. A palpação do abdome evidenciou sinais de peritonite e a percussão mostrou timpanismo no hipocôndrio direito. A radiografia de tórax confirmou o diagnostico de perfuração com a presença de pneumoperitôneo.
O achado cirúrgico foi uma tumoração de aproximadamente $12 \mathrm{~cm}$ em seu maior diâmetro, consistência firme, multilobulada e recoberta com fibrina (Figura 1). Não havia sinais de linfadenomegalia mesentérica ou retroperitoneal. Foi realizada uma enterectomia com ressecção ampla do mesentério e recontrução do trânsito por uma ênteroenteroanastomose primária. Houve boa evolução pósoperatório, com alta no $6^{\circ}$ dia.

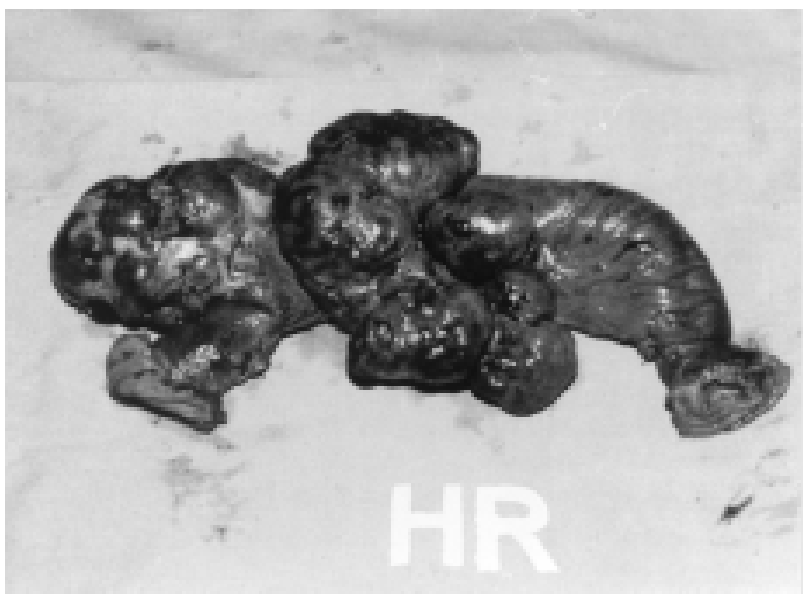

Figura 1 - Tumor intestinal multilobulado medindo cerca de $12 \mathrm{~cm}$. Observe a fibrina recobrindo a massa.

O estudo histopatológico diagnosticou um leiomioma jejunal perfurado, sem evidências de mitose ou sinais de invasão linfática e vascular (Figura 2). Após cinco anos de seguimento, o paciente permanece assintomático e pode ser considerado curado.

\footnotetext{
1. Cirurgião da Emergência de Adultos - Hospital da Restauração.

2. Neurocirurgia da Emergência de Adultos - Hospital da Restauração.

3. Acadêmico de Medicina da Universidade Federal de Pernambuco.
}

\section{Recebido em 26/12/2002}

Aceito para publicação em 12/12/2003

Trabalho realizado no Hospital da Restauração, Secretaria de Saúde do Estado de Pernambuco e apresentado na Seção de Temas Livres do $23^{\circ}$ Congresso Brasileiro de Cirurgia, Recife 1997. 


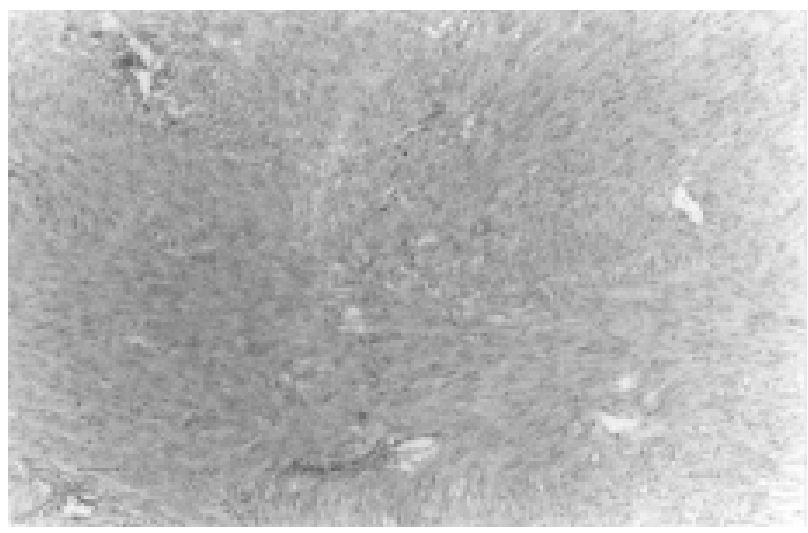

Figura 2 - Corte histológico contendo celulas musculares lisas bem diferenciadas. Nenhuma mitose foi vista.

\section{DISCUSSÃO}

O leiomioma e a mais comum lesão benigna sintomática do intestino delgado. É usualmente diagnosticado na $5^{\circ}$ década de vida, mas pode ocorrer em qualquer idade. Não há predileção por sexo. A maioria são jejuno-ileais, porém existe uma desproporcional alta incidência no divertículo de Meckel e no duodeno se considerarmos por unidade de área ${ }^{1,4}$.

Quando sintomáticos, 54\% dos leiomiomas causam dor abdominal e $45 \%$ provocam hemorragia. Obstrução aguda com ou sem intussepção é mais incomum, e uma massa palpável ou perfuração e extremamente raro $^{2,4}$. A enterorragia causada por um leiomioma é frequientemente maciça e recorrente, com variação nos intervalos de resangramento ${ }^{4}$.
Os leiomiomas podem apresentar quatro formas de crescimento na parede intestinal: extraluminal (65\%), intramural (16\%), intra/extraluminal (11\%) e intraluminal $(8 \%)^{1}$. Os tumores benignos tendem a ser menores que as lesões malignas. Metade dos leiomiomas relatados na literatura eram $<5 \mathrm{~cm}$ e metade dos leiomiossarcomas tinham entre 5 e $9 \mathrm{~cm}$ de diametro ${ }^{3}$.

Em relação à perfuração, Wilson et $a l^{2}$ comentam na revisão de casos da Universidade de Cornell que apenas sete casos haviam sido relatados na literatura, sendo seis leiomiomas. O próximo relato aconteceu em 1992, quando Wilson e Wheeler descreveram o caso de um leiomioma gigante $(25 \mathrm{~cm}$ e $2.2 \mathrm{Kg}$ ) perfurado após a realização de uma tomografia computadorizada do abdome ${ }^{4}$.

Recentemente, patologistas têm iniciado uma mudança de terminologia de leiomioma/leiomiossarcoma para tumores estromais gastrointestinais ("GIST"). A imunohistoquímica é a maior arma para desvendar a diferenciação desses tumores. A difícil diferenciação entre tumores estromais malignos e benignos ainda se baseia no achado microscópico de mais de duas mitoses por campo (aumento 10X). A presença de menos que duas mitoses está associado a um excelente prognóstico e uma elevada sobrevida em cinco anos $^{5}$.

Apesar de tratar-se de um caso com um tumor grande e perfurado, a ausência de mitoses e o seguimento a longo prazo (cinco anos) caracterizam a benignidade do tumor muscular aqui relatado.

\begin{abstract}
A perforated jejunal leiomyoma is a rare condition; only seven cases have been described in the literature. We report a case of a 45 years old man with a perforate acute abdomen. At laparotomy, a $12 \mathrm{~cm}$ multilobulated firm mass, located $20 \mathrm{~cm}$ distal from Treitz ligament, was removed. Histological sections disclosed a jejunal leiomyoma. The benign pattern of the lesion was confirmed with no mitosis and no atypical cellurarity. Five years later, the patient is free of the disease.
\end{abstract}

Key Words: Intestine, small; Neoplasm; Leiomyoma; Intestinal perforation.

\section{REFERÊNCIAS}

1. Burgos AA, Martinez ME, Jaffe BJ - "Tumors of the small intestine". In Zinner MJ (ed) - Maingot's abdominal operations. $10^{\circ}$ Edition. Connecticut. Appleton \& Lange, 1997, pp. 1131-1173.
2. Wilson JM, Melvin DB, Gray G, et al. - Benign small bowel tumor. Ann Surg, 1975, 181(2):247250.

3. Blanchard DK, Budde JM, Hatch GF, et al. Tumors of the small intestine. World J Surg, 2000, 24(4):421-429. 
4. Wilson SL, Wheeler WE - Giant leiomyoma of the small intestine with free perforation into the peritoneal cavity. South Med J, 1992, 85(6):667-668.

5. Gill SS, Heuman DM, Mihas AA - Small intestinal neoplasms. J Clin Gastroenterol, 2001,33(4):267282.
Endereço para correspondência:

Antonio Cavalcanti de Albuquerque

Rua Deputado Pedro Pires Ferreira, 325 / 1601 - Graças 52050-480 - Recife - PE

Phone: (81)9973-8223 / (81) 3267-2670

E-mail: acam@elogica.com.br 